\title{
UNUSUAL PRE-OXIDIZED POLYACRYLONITRILE FIBRES BEHAVIOUR AGAINST THEIR ACTIVATION WITH CO2: CARBONIZATION EFFECT
}

\author{
G. Trautwein*, M. Plaza-Recobert, J. Alcañiz-Monge \\ Dpto. Química Inorgánica, Universidad de Alicante, E-03080 Alicante, Spain
}

\begin{abstract}
.
The CF-PAN activation process with $\mathrm{CO}_{2}$ has been analysed. Activation of CF-PAN with $\mathrm{CO}_{2}$ leads to unusual results both, activation percentage evolution over the time and generated porosity development. In the explanation has been highlighted the role of the carbonization step in the CF-PAN activation process. The analysed results point to the fact that part of the released nitrogen-containing compounds during PANOX fibres carbonization are deposited on the CF surface, which affects to carbonized PAN fibres, decreasing actives sites, or acting as inhibitors of the gasification reaction.
\end{abstract}

* Corresponding Author. Fax: +34 965909419. E-mail address:

guido.trautwein.clerici@gmail.com

Keywords: Polyacrylonitrile Carbon Fibres, Activated Carbon Fibres, Reactivity, $\mathrm{CO}_{2}$ Activation, Microporosity. 


\section{Introduction.}

Using carbon fibres $(\mathrm{CF})$ to prepare activated carbon fibres (ACF) becomes interesting since they show several advantages regarding to conventional activated carbons (AC) (granular, powder...) due to their higher performances, such as greater adsorption capacity and higher adsorption/desorption velocities (Donnet et al. 1998, Ryu 1990, Ryu et al. 1993). In this sense, several studies are being carried out on the preparation of activated carbon fibres or carbon clothes, mainly from rayon (Mcnair et al. 1997, Freeman et al. 1989), and coal tar pitch (Suzuki et al. 1994). In the case of rayon, mechanical properties of the obtained fibres are low, as well as the yield (around $25 \%$ regarding to carbonization process). On the other hand, coal tar pitch shows higher yields (around 70-80 \% regarding to carbonization process) (Alcañiz-Monge et al. 1997) that together with its lower cost, makes it an interesting material from which obtaining carbon fibres. Some studies have demonstrated that physical activation (based on a controlled gasification of the carbonaceous material) with $\mathrm{CO}_{2}$ is the most effective method to obtain a higher microporosity development in the bulk of the coal tar pitch based CF (AlcañizMonge et al. 1994, Alcañiz-Monge et al. 1997).

Regarding to $\mathrm{CF}$ based on polyacrylonitrile (PAN), compared to the above mentioned precursors, their activation has been less studied because that leads to ACF with lower adsorption capacities (Park et al 2001, Ko et al. 1992, Tavanai et al. 2009). In spite of this, ACF based on PAN (CF-PAN), due to their structural nitrogen intrinsic content, are interesting for applications such as gaseous pollutants and volatile organic compounds adsorbents or basic catalysts (Mochida et al. 2000, Song et al. 2007, Zaini et 
al. 2010). The best CF-PAN results have been obtained by chemical activation process, while physical activation, especially with $\mathrm{CO}_{2}$ leads to low porosity values $\left(600 \mathrm{~m}^{2} / \mathrm{g}\right.$ ACF-PAN Vs. $1800 \mathrm{~m}^{2} / \mathrm{g}$ ACF-Pitch)( Park et al. 2001, Ko et al. 1992, Tavanai et al. 2000, Wang et al. 1996).

Taking into account the above mentioned, the goal of this work is to study the CF-PAN activation process with $\mathrm{CO}_{2}$, highlighting the role of the initial carbonization step in the CF-PAN activation process.

\section{Experimental.}

\subsection{Materials and Methods.}

\subsubsection{Carbonization of PANOX fibres}

In this work, pre-oxidized commercial PAN fibres PANOX $^{\circledR} \quad$ (SGL $^{-}$ TECHNOLOGIES GmbH) were employed (the use of pre-oxidized PAN fibres instead PAN fibres is intended to prevent melting or fusion of fibres in the subsequent carbonization step) (320k filaments, with a fibre's density of $1.39 \mathrm{~g} / \mathrm{cm}^{3}$, $230 \mathrm{MPa}$ of tensile strength). Fibres were carbonized in a quartz reactor, with $6 \mathrm{~cm}$ of internal diameter and $150 \mathrm{~cm}$ of length, placed inside of a horizontal oven (contained in $\mathrm{N}_{2}\left(100 \mathrm{~cm}^{3} / \mathrm{min}\right)$ at two different temperatures, 850 and $1000{ }^{\circ} \mathrm{C}$, with a $10^{\circ} \mathrm{C} / \mathrm{min}$ heating rate and hold for 30 minutes at the maximum carbonization temperature. In 
these experiments, the effect of the final carbonization temperature and the amount of matter used on the final CF-PAN yield were analysed.

\subsubsection{Activation of CF-PANs.}

With the aim to compare the results of the present work with those obtained by other authors on the petroleum pitch carbon fibres (CFP) activation, the activation was realized at $890^{\circ} \mathrm{C}$ (Alcañiz-Monge et al. 1994, Vilaplana-Ortego et al. 2008). CF-PANs (1 gram) were activated in a horizontal oven applying the following thermal treatment: heated in $\mathrm{N}_{2}$ flow $\left(100 \mathrm{~cm}^{3} / \mathrm{min}\right.$, superficial gas velocity of $3.4 \mathrm{~cm}^{3} / \mathrm{min}$, at 1 bar and 25 $\left.{ }^{\circ} \mathrm{C}\right)$ to $890{ }^{\circ} \mathrm{C}$, switched to $\mathrm{CO}_{2}$ flow $\left(100 \mathrm{~cm}^{3} / \mathrm{min}\right)$ and hold at this temperature for different periods of time. Additionally, the experiments were realized using water vapour stream $\left(\mathrm{H}_{2} \mathrm{O} / \mathrm{N}_{2} 40 / 40 \mathrm{~cm}^{3} / \mathrm{cm}^{3}\right)$. The burn-off percentage (BO) was determined by mass balance. In the nomenclature of the activated samples both, the $\mathrm{BO}$ and the activation agent are indicated $\left(\mathrm{CO}_{2}-\mathrm{C}, \mathrm{H}_{2} \mathrm{O}-\mathrm{S}\right)$ (i.e. CFPAN activated with $\mathrm{CO}_{2}$ and 47 $\%$ BO, CFPAN47C).

\subsection{Characterization.}

The PANOX fibres carbonization process together with released gases was studied by thermogravimetric analysis and mass spectrometry (TG-MS), respectively, with a TA-SDT 680 instrument. For that, $10 \mathrm{mg}$ of PANOX fibres were placed in the thermobalance and subjected to a thermal treatment in He atmosphere $\left(60 \mathrm{~cm}^{3} / \mathrm{g}\right)$, with a 
gas output coupled to a quadrupolar mass spectrometer (Balzers Quadstar model). The temperature program used was the following: heated to $1000{ }^{\circ} \mathrm{C}$ at $20{ }^{\circ} \mathrm{C} / \mathrm{min}$. This allowed analysing the weight loss and the evolved gases by the PANOX fibres decomposition.

The carbon, nitrogen and hydrogen content of the original PANOX fibres, the $\mathrm{CF}$ and the ACF was determined using a Carlo Erba EA 1110CHNS-O instrument, while the oxygen content was estimated from the previous values, taking into account that other heteroatoms do not exist in the fibres.

The nature of the CF-PAN surface before and after the activation was analysed by X-ray photoelectron spectroscopy (XPS). XPS experiments were realized at room temperature in high vacuum conditions $\left(5.10^{-8}\right.$ bars $)$ with a VG-Microtech Multilab 3000 instrument. This instrument consists of a monochromatic X-Ray radiation source $\mathrm{Mg}-\mathrm{K} \alpha(1253.6 \mathrm{eV})$. For energy calibration, it was selected as reference the 1s carbon transition belonging to graphite, which value is $284.6 \mathrm{eV}$ (Wang et al. 1994). Atomic ratios were estimated from the relative ratio between XPS spectra peak areas, corrected by an intensity factor calculated using the Scofield method (Scofield et al. 1976).

Porous texture of the ACF was characterized by gas physical adsorption $\left(\mathrm{N}_{2}\right.$ at $196{ }^{\circ} \mathrm{C}$ and $\mathrm{CO}_{2}$ at $0{ }^{\circ} \mathrm{C}$ ) (Autosorb 6-B and Autosorb-6, respectively). Before realizing the adsorption tests, the samples were treated by vacuum at $250{ }^{\circ} \mathrm{C}$ during 4 hours. The surface area was determined by BET equation (Brunauer et al. 1938). DubininRadushkevich equation (DR) (Dubinin et al. 1966) was employed to calculate the pore 
volume distribution (Cazorla-Amorós et al. 1996): a) narrow micropore volume (pore size $<0.7 \mathrm{~nm}$ ), called ultramicropores, $\mathrm{V}_{\mathrm{CO} 2}$, was estimated from $\mathrm{CO}_{2} \mathrm{DR}$ plots (relative pressures $<0.015$ ); (b) total micropore volume (pore size $<2 \mathrm{~nm}$ ), $\mathrm{V}_{\mathrm{N} 2}$, was calculated from $\mathrm{N}_{2}$ DR plots (relative pressures $<0.14$ ).

\section{Results and Discussion.}

\subsection{Carbonization of PANOX fibres.}

Figures 1 and 2 show the TG curve and the profile of the released gases, respectively. It must be pointed out that, the thermal treatment of the PAN fibres has been extensively studied due to the final mechanical features of the obtained CF are hardly dependent of the conditions in which it is realized. Therefore, and taking into account that it is not the main goal of this work and the existence of a wide literature about it (Fitzer et al. 1986, Rahaman et al. 2007, Yusofa et al. 2012), a strict analysis of the results presented in Figures 1 and 2 will not be realized. In summary, PANOX fibres carbonization produces an important loss of mass, higher than $50 \%$ (Figure 1), which takes place mainly through the volatile release, above all as oxygen-containing compounds $\left(\mathrm{CO}, \mathrm{CO}_{2}, \mathrm{H}_{2} \mathrm{O}\right)$ and nitrogen-containing compounds $\left(\mathrm{NH}_{3}, \mathrm{HCN}, \mathrm{CH}_{3} \mathrm{CN}\right)$ (Figure 2), which leads to a carbon enrichment of the final CF.

As can be observed in Figure 1, the volatile release takes place in three stages (Jing et al. 2007, Wangxi et al. 2003). In the first stage, at 200-350 ${ }^{\circ} \mathrm{C}$, cross-linking reactions between oxidized PAN polymer chains take place, through radicals generated by the 
decomposition of terminal oxygen-containing and nitrogen containing groups (Figure 2). In the second stage, at the region of $350-550{ }^{\circ} \mathrm{C}$, it takes place an important pyrolytic decomposition, mainly of PAN fibres or fragments of these, which have not been able to stabilize themselves by cross-linked bonds. In this way, a large amount of nitrogencontaining compounds together with oxygen-containing groups, mainly $\mathrm{CO}_{2}$ and $\mathrm{H}_{2} \mathrm{O}$, which were originated in the oxidation process of the PAN fibres to obtain the stabilized PANOX fibres, are produced, (Figure 2). As a consequence of these decompositions, a large amount of radicals is generated. At the same time, a rearrangement of the linear molecular segments takes place, leading to cyclization reactions, developing planar carbonaceous structures, which will lead to an aromatization process of the carbonaceous structure which begins to take place in the third stage, at $550-700{ }^{\circ} \mathrm{C}$. For temperatures higher than $600{ }^{\circ} \mathrm{C}$, condensation reactions between heterocyclic rings happens, releasing gases like $\mathrm{HCN}$ and $\mathrm{NH}_{3}$ (Park et al. 2001). When the temperature exceeds $700{ }^{\circ} \mathrm{C}$, it takes place a higher structure aromatization, through dehydrogenation and denitrogenation reactions $\left(\mathrm{HCN}\right.$ and $\left.\mathrm{N}_{2}\right)$, and the growing of aromatic structures (Mittal et al. 1998, Watt et al. 1985).

Taking into account the above commented and that up to $850{ }^{\circ} \mathrm{C}$ it does not take place an important loss of mass, the carbonization process was realized at $1000{ }^{\circ} \mathrm{C}$, as usual when active carbon precursors are used. Furthermore, taking into account the loss of mass that takes place during the carbonization process and the $\mathrm{CO}_{2}$ activation, it turns out important to use an amount of sample as large as possible. Therefore, the effect of the initial fibres amount on the final yield at two different temperatures was studied. The obtained results are presented in Table 1. 
Table 1. Carbonization yield (\% weight)

\begin{tabular}{|l|c|c|c|}
\hline & Grams & \multicolumn{2}{c|}{ Temperature $\left({ }^{\circ} \mathbf{C}\right)$} \\
\hline & & 850 & 1000 \\
\hline 1PAN & 1 & 50 & 44 \\
\hline 5PAN & 5 & 52 & 47 \\
\hline 10PAN & 10 & 57 & 51 \\
\hline 20PAN & 20 & 58 & 52 \\
\hline
\end{tabular}

As can be appreciated, the obtained results with a small amount, 1 gram, are similar to that obtained by TG (10 mg) (Fig. 1). This fact indicates, as was expected, that there are not diffusive problems for the output of the pyrolytic decomposition products. The higher the fibres amount, the higher the packing of them. In these conditions, the output of the volatile compounds is more hindered. As a consequence, a higher yield was obtained. However, this effect is restricted to a certain amount. Therefore, up to 10 grams it can be observed a yield rise (7\%), which is quite similar to that obtained with double amount. Finally, it must to be pointed out that this increase of the yield takes place for temperatures below $850{ }^{\circ} \mathrm{C}$, since for higher temperatures the losses are quite similar regardless of the employed amount $(6 \%)$. This result is in agreement with the volatile amount released, which takes place mainly at temperatures below $850{ }^{\circ} \mathrm{C}$ (Fig. 2), supporting the hypothesis that the increase of the yield should be related to the greater difficulty in volatiles release.

At this point, it will be analysed the reason of the above mentioned increase of the yield. To do that, it was determined the elemental composition of both, the superficial (XPS) and the whole fibres (elemental analysis). Results are shows in Table 2. 
Table 2. Global elemental analysis (\% weight) and superficial (\% at) determined by XPS of the original PANOX fibres and carbonized at $1000{ }^{\circ} \mathrm{C}$

\begin{tabular}{|c|c|c|c|c|c|c|c|}
\hline & \multicolumn{4}{|c|}{ Global (\% weight) } & \multicolumn{3}{|c|}{ Superficial (XPS) (\% at) } \\
\hline & $\mathbf{C}^{\mathbf{a}}$ & $\mathbf{N}^{\mathbf{a}}$ & $\mathbf{O}^{\mathrm{a}}$ & $\mathbf{H}$ & $\mathbf{C}$ & $\mathbf{N}$ & $\mathbf{0}$ \\
\hline PANOX & $62.5(69.6)$ & $16.4(15.7)$ & $17.6(14.7)$ & 3.5 & 65.7 & 13.7 & 20.6 \\
\hline CF 1PAN & $83.4(88.1)$ & $2.7(2.4)$ & $12(9.5)$ & 1.9 & 86.1 & 2.7 & 11.2 \\
\hline CF 10PAN & $84.2(88.5)$ & $4.0(3.6)$ & $10(7.9)$ & 1.8 & 85.7 & 5.2 & 9.1 \\
\hline CF 20PAN & $84.8(89.0)$ & $4.4(4.0)$ & $9(7.1)$ & 1.8 & 85.3 & 6.5 & 8.2 \\
\hline
\end{tabular}

As expected, comparing PANOX values with those obtained with 1PAN fibres, the carbonization process leads to carbon enrichment and a decrease of the rest of heteroatoms, especially nitrogen. This fact is in agreement with released volatiles compounds (Figure 2). The carbonization process of large amount of PANOX fibres affects mainly the nitrogen content of resulting CF. This effect could be attributed to lower nitrogen-containing compounds decomposition, as a consequence of the increase in the vapour pressure that takes place when the amount of volatile compounds is released. However, XPS results evidence that this is not the reason. So, while for CF 1PAN the nitrogen content on the surface is similar to the whole value, which indicates that $\mathrm{N}$ is homogeneously distributed in the bulk of the fibres; $\mathrm{CF} 10 \mathrm{PAN}$ and 20PAN XPS results show higher nitrogen values, the greater, the greater is the carbonized amount. These results indicate that a nitrogen superficial enrichment during the fibres carbonization process has happened, which should be attributed to a solid nitrogen enriched deposit formation on the surface of the carbonized PANOX fibres. The development of these kinds of superficial deposits, described by other authors, happens 
as a consequence of secondary reactions between the released volatile compounds or between the last with radicals generated on the surface of the carbonized (Megaritis et al. 1998, Messenböck et al. 1999, Froment et al. 1990). The above considerations allow explaining the nitrogen superficial enrichment and the obtained yield.

\section{2. $C F-P A N$ activation.}

Taking into account the higher yield obtained at $1000{ }^{\circ} \mathrm{C}$ using 10 grams of PANOX, CF were prepared under these conditions for studying their activation with $\mathrm{CO}_{2}$ (10PAN). CF 10PAN activation results, together with the bibliographic CFP results (Alcañiz-Monge et al. 1994, Vilaplana-Ortego et al. 2008), are showed in Figure 3. The figure includes the results of the CF 1PAN activation, as well as those obtained from two consecutive 10 PAN activations, which description will be detailed throughout this section.

As it can be appreciated, CF prepared from different precursors show differences in their burn-off percentage evolution. So, initially, CFP show a high activation rate (obtained from the slope), indicating a high reactivity towards $\mathrm{CO}_{2}$ gasification process, which decreases in accordance with the CF activation process. This behaviour, typical of carbonization activation processes, is related to a decrease in the number of active sites present on the surface of the carbonized, (superficial oxygen-containing groups and defects in the graphitic sheets) according to the material gasification development (Chiang et al. 2007). The behaviour of the CF 10PAN is completely opposite. Therefore, initially (1 hour), it shows a low activation rate, indicating an initial CF 10PAN low 
reactivity (5\% BO vs $15 \% \mathrm{BO}$ of $\mathrm{CFP}$ ). However, the higher the activation time, the higher the slope of the activation percentage curve, whereas that of CFP shows a similar slope for all activation times. So that, for activation percentages higher than $20 \%$, CF 10PAN show a reactivity higher than that showed by CFP (denoted by a higher slope of the activation curve). This behaviour is usually observed in reactions where exist inactive species, metallic catalysts or metallic oxides, which are activated during the reaction (Boehm et al. 1970). In this case, the increase cannot be attributed to this effect since there are not metallic species in PANOX fibres. Therefore, the observed tendency could take place as a consequence of: a) initial inaccessibility of $\mathrm{CO}_{2}$ to the active sites, b) the nature of the superficial groups existing on the surface of these materials (nitrogencontaining groups (Chiang et al. 2007), which confer them this different behaviour).

Another striking result for the CF 10PAN was found when the ACF obtained from those were again activated; with the aim to take an advantage of ACF 10PAN, which were barely activated (i.e. ACF obtained after $2 \mathrm{~h}$ of activation, with $10 \% \mathrm{BO}$ ), these were subjected to a second activation (at different times, $3 \mathrm{~h}$ and $5 \mathrm{~h}$ ). In contrast to that expected, ACF reactivity was significantly increased (Figure 3, Second series). In addition, it was observed that this behaviour was depending on the ACF activation degree. Therefore, additional activation of 2 hours with greater activation degree than previous (obtained after 5 hours with $33 \% \mathrm{BO}$ ), led to a $\mathrm{BO}$ percentage correlated to the above mentioned tendencies (Figure 3, Second series). For comparative purposes, the figure includes the global $\mathrm{BO} \%$ (referred to initial amount) of $\mathrm{ACF}$ which have been subjected to two activations. From these values it can be appreciated that can be 
obtained ACF with different BO percentages, in spite of being subjected to the same global activation time (7 hours).

The CF 1PAN activation obtained results (obtained from a small amount during the carbonization process) will help us to explain the previous results. As can be observed in Figure 3, CF 1PAN show an elevated initial reactivity, which decreases slightly in accordance with the sample activation, comparable with that showed by ACF 10PAN in their second activation. This different behaviour, as well as the increased activity observed in ACF 10PAN after a second activation, should be directly related to different PANOX fibres carbonization conditions, which ultimately, should affect to CF active sites. In Table 3 are listed the results obtained for ACF which similar activation percentage (close to $35 \% \mathrm{BO}$ ) by XPS and elemental analysis. Table includes, for comparative purposes, results above mentioned for CF 10PAN (Table 2).

Table 3. Elemental analysis (\% weight) and superficial composition (\% at) determined by XPS for CF $10 \mathrm{PAN}$ and $\mathrm{ACF}(\approx 35 \% \mathrm{BO})$ obtained from different $\mathrm{CF}$ in increasing carbonization order; 1PAN, 10PAN and 20PAN, respectively.

\begin{tabular}{|c|c|c|c|c|c|c|c|}
\hline & \multicolumn{4}{|c|}{ Global (\% weight) } & \multicolumn{3}{|c|}{ Superficial (XPS) ( \% at) } \\
\hline & $\mathbf{C}^{\mathbf{a}}$ & $\mathbf{N}^{\mathbf{a}}$ & $\mathbf{O}^{\mathbf{a}}$ & $\mathbf{H}$ & $\mathbf{C}$ & $\mathbf{N}$ & $\mathbf{O}$ \\
\hline CF 10PAN & $84.2(88.5)$ & $4.0(3.6)$ & $10(7.9)$ & 1.8 & 85.7 & 5.2 & 9.1 \\
\hline ACF 1PAN & $81.9(86.4)$ & $1.6(1.4)$ & $15.3(12.1)$ & 1.2 & 78.4 & 1.6 & 20 \\
\hline ACF 10PAN & $82.0(86.5)$ & $2.3(2.1)$ & $14.5(11.5)$ & 1.2 & 80.6 & 1.9 & 17.5 \\
\hline ACF 20PAN & $82.4(86.7)$ & $2.5(2.3)$ & $14(11.0)$ & 1.1 & 81.9 & 2.1 & 16 \\
\hline
\end{tabular}

${ }^{a}$ values in parenthesis $\%$ atomic. Calculated respect to $\Sigma(\mathrm{C}+\mathrm{N}+\mathrm{O})_{\mathrm{at}}$ 
Observed differences between original CF and ACF and between CF 10PAN and ACF 10PAN are in agreement with those expected (Boehm et al. 1970, RaymundoPiñero et al. 2000): oxygen enrichment, as superficial oxygen-containing groups, which is confirmed by higher atomic ratio obtained by XPS. Much more significant for this work is the similitude between values showed by ACF, especially those referred to nitrogen content. Therefore, it can be observed as the nitrogen content decreases considerably after activation (compare Table 2 and Table 3 results), showing lower nitrogen contents on the ACF surface, as can be deduced from XPS results.

Therefore, it should be reasonable to think that nitrogen-containing compounds deposition on the ACF surface (without discarding a certain pyrolytic carbon fraction) (Table 2) block active sites, decreasing for 1PAN samples. The gradual CF 10PAN reactivity's increase can be explained considering that the activation removes nitrogencontaining compounds from the surface (Figure 3). Nevertheless, the considerable reactivity's increase observed after the first activation process, independently of ACF BO (i.e. 10-33\%) does not match with the active sites blockage. It also must be mentioned the result obtained after a double activation $(2+3$ hours $)$ without removing ACF from the oven after the first one (after 2 hours, the oven was cooled to room temperature applying a $\mathrm{N}_{2}$ stream and afterwards ACF were heated and activated for 3 hours more). In this case there was not observed any change on the CF reactivity, despite being similar to 5 hours simple activation process (Figure 3). This highlights that ACF are affected by the atmosphere exposure. In this sense, taking into account the air exposure, it seems to be reasonable thinking that the nitrogen-containing compounds removal is favoured by their interaction with environmental moisture. 
With the aim to deepen this aspect, CF 10PAN activation in water/nitrogen $\left(\mathrm{H}_{2} \mathrm{O} / \mathrm{N}_{2}\right)$ stream was realized. Obtained results are showed in Figure 4, which also contains bibliographic results obtained from a CFP in similar experimental conditions. For CFP, it can be observed as $\mathrm{H}_{2} \mathrm{O}$ (v) reactivity is three time higher than that observed for $\mathrm{CO}_{2}$ despite the first one pressure is half than the last, which is in agreement with that observed by other authors (Alcañiz-Monge et al. 1994, Walker et al. 1959, Rhyu et al. 1993). The CF 10PAN activated with $\mathrm{H}_{2} \mathrm{O}$ leads to high $\mathrm{BO} \%$ from the beginning of the reaction, which indicates the $\mathrm{CF}$ 10PAN reactivity is much higher than PCF. In fact, several studies have indicated the catalytic nitrogen-containing compounds effect for certain reactions (Raymundo-Piñero et al. 2003). By one side, this fact is in disagreement with the low reactivity observed against $\mathrm{CO}_{2}$, and by other one, it supports the hypothesis of the increase on the CF PAN activation after a second activation. In this sense, the low reactivity observed in this work would be in accordance with the results obtained by other authors regarding to the inhibitor effect of nitrogen incorporation on microcrystalline carbons oxidation (Mang et al. 1992).

To conclude with this section, the analysed results point to the fact that part of the released nitrogen-containing compounds during PANOX fibres carbonization are deposited on the CF surface, which affects to carbonized PAN fibres, decreasing actives sites or acting as inhibitors of the gasification reaction. Once eliminated, a considerable increase on the $\mathrm{CF}$ 10PAN reactivity is produced, comparable to that observed for $\mathrm{CF}$ 1PAN, on which a scarcely deposit takes place. 


\subsection{ACF PAN porous texture characterization.}

Regarding to their potential applications, the porosity of the ACF is their most important property. For that reason, the porous texture of ACF and CF 10PAN was analysed by physical gas adsorption technique $\left(\mathrm{N}_{2}\right.$ a $-196{ }^{\circ} \mathrm{C}$ y $\mathrm{CO}_{2}$ a $\left.0{ }^{\circ} \mathrm{C}\right)$. Figure 5 shows the obtained $\mathrm{N}_{2}$ isotherms.

Regarding to the isotherm shape analysis, it must be remarked the following aspects: i) the adsorption magnitude at $\mathrm{P} / \mathrm{P}_{\mathrm{o}}<0.3$, which is related to specific micropores volume, ii) the isotherm knee, related to micropore size distribution, iii) adsorption at $\mathrm{P} / \mathrm{P}_{\mathrm{o}}$ $>0.3$ and iv) the presence of an hysteresis cycle, which indicates mesopore presence. $\mathrm{CF}$ 10PAN do not show $\mathrm{N}_{2}$ adsorption isotherm, indicating that the sample is not porous or the presence of narrow microporosity (pore size $<0.7 \mathrm{~nm}$ ) where $\mathrm{N}_{2}$ adsorption does not take place. On the other hand, all of ACF show adsorption at low relative pressures $(<0.3)$, which is characteristic of Type I isotherms, according to IUPAC classification (Sing et al. 1985). This indicates the essentially microporous nature of ACF-PAN, as has been observed in previous works (Park et al. 2001, Ko et al. 1992, Tavanai et al. 2009, Wang et al. 1996). The most interesting aspect of this chapter is the microporosity development given by the activating agents. Therefore, for low $\mathrm{BO} \%$, both activating agents produce similar isotherms regarding to the adsorbed $\mathrm{N}_{2}$ amount and the shape. For samples with medium BO \% (close to $50 \%$ ), there are some differences between both series. So, while water vapour stream activation mainly produces new microporosity, as can be observed in the increase of the adsorption capacity at $\mathrm{P} / \mathrm{Po}<0.1$, activation with $\mathrm{CO}_{2}$ leads to a microporosity widening, as can be deduced from de wide knee of the isotherm. This 
behaviour is opposite to that observed in $\mathrm{CF}$ and $\mathrm{ACF}$ with other precursors, using both activating agents (Alcañiz-Monge et al. 1994, Cazorla-Amorós et al. 1996, VilaplanaOrtego et al. 2008, Rhyu et al. 1993). For high BO \% values, activation with both agents is similar, since there is any porosity generation. This fact indicates that it takes place the outer burning of ACF. This result has been observed by other authors and it is related to the microporosity collapse for higher BO \% values (Rhyu et al. 1993).

With the aim to complete the ACF PAN characterization, Table 4 shows BET specific surface values and porosity volumes of ACF 10PAN calculates from $\mathrm{N}_{2}$ and $\mathrm{CO}_{2}$ isotherms data, together with two CFP (Cazorla-Amorós et al. 1996).

Table 4. Porous texture characterization of ACF based on PAN fibres and CFP.

\begin{tabular}{lccc}
\hline & $S_{\text {BET }}\left(\mathrm{m}^{2} / \mathrm{g}\right)$ & $\mathrm{V}_{\mathbf{N} 2}\left(\mathrm{~cm}^{\mathbf{3}} / \mathrm{g}\right)$ & $\mathrm{V}_{\mathrm{CO} 2}\left(\mathrm{~cm}^{3} / \mathrm{g}\right)$ \\
\hline CF 10PAN & - & - & 0.07 \\
\hline CFPAN18C & 375 & 0.18 & 0.10 \\
CFPAN47C & 400 & 0.23 & 0.11 \\
CFPAN73C & 190 & 0.10 & 0.05 \\
\hline CFPAN20S & 366 & 0.17 & 0.12 \\
CFPAN58S & 500 & 0.24 & 0.15 \\
CFPAN84S & 530 & 0.25 & 0.17 \\
\hline CFP54C & 1930 & 0.85 & 0.75 \\
CFP60S & 1710 & 0.69 & 0.51 \\
\hline
\end{tabular}

It is important to remark that the microporosity volume obtained from the $\mathrm{N}_{2}$ adsorption corresponds to the whole range of microporosity (pore size up to $2 \mathrm{~nm}$ ), while the $\mathrm{CO}_{2}$ adsorption only provides information about narrow microporosity $(<0.7$ nm) (Mittal et al. 1998, Megaritis et al. 1998, Messenböck et al. 1999, Froment et al. 
1990). Hence, the comparison of both, $\mathrm{V}_{\mathrm{CO} 2}$ and $\mathrm{V}_{\mathrm{N} 2}$, gives us an idea about the size of the ACF micropores. Firstly, it is important to highlight the existence of a microporosity in $\mathrm{CF}$ 10PAN, which shows $\mathrm{CO}_{2}$ adsorption but is not affected by $\mathrm{N}_{2}$ adsorption (Figure 5). This behaviour is owed to the existence of restrictions, which hinder the $\mathrm{N}_{2}$ diffusion in the microporosity bulk (Fitzer et al. 1986, Rahaman et al. 2007). This behaviour has been observed in other PCF and for carbonized (Cazorla-Amorós et al. 1996, Rahaman et al. 2007; Rhyu et al. 1990). The total and narrow microporosity volumes ACF evolution, $\left(\mathrm{V}_{\mathrm{N} 2}\right)$ and $\left(\mathrm{V}_{\mathrm{CO} 2}\right)$ respectively, are in agreement to $\mathrm{N}_{2}$ isotherm discussion above commented. For this reason, $\mathrm{CO}_{2}$ activation hardly develops microporosity, focusing on its widening, increasing $\mathrm{V}_{\mathrm{N} 2}$ and $\mathrm{V}_{\mathrm{CO} 2}$ difference, while water vapour activation leads to a continuous increase of the narrow microporosity, $\mathrm{V}_{\mathrm{CO} 2}$. Finally, it is important to remark that water vapour activation produces ACF with a higher porous texture development, as much in BET surface as microporosity volume. However, the obtained values are relatively lower than those obtained from CFP under the same experimental conditions.

As a resume, obtained results highlight differences between $\mathrm{CO}_{2}$ and $\mathrm{H}_{2} \mathrm{O} C F$ 10PAN activation. These differences are observed in both, the reactivity of activating agents towards the CF 10PAN gasification process and the $\mathrm{CF}$ porosity development. Comparing results of the present work to those found in the bibliography it can be conclude that $\mathrm{CO}_{2}$ activation leads to unusual results.

The explanation of the unusual $\mathrm{CO}_{2}$ activation process should be related to the active sites blockage by nitrogen-containing compounds pyrolytic deposit development, 
which, taking into account the obtained results, are resistant to the attack of $\mathrm{CO}_{2}$ molecule, so not towards $\mathrm{H}_{2} \mathrm{O}$ molecule. Considering as correct the $\mathrm{CO}_{2}$ reactivity towards nitrogen-containing deposits, it can be established how the CF 10PAN activation process takes place: initially $\mathrm{CO}_{2}$ activation takes place mainly in the available active sites, free of nitrogen-containing deposits. Therefore, the gasification process located in these places initially produces microporosity. As the activation progresses the availability of free nitrogen-containing active sites decreases (Figure 3, reactivity remains at the same value). So, the activation process continues in the previously generated micropores. Therefore, the $\mathrm{CO}_{2}$ activation is focused on widening the original microporosity, producing its collapse at high $\mathrm{BO} \%$ values.

\section{Conclusions}

Activation of $\mathrm{CF}$ PAN with $\mathrm{CO}_{2}$ leads to unusual results both, activation percentage evolution over the time and generated porosity development. Therefore, it initially shows a low activation rate, which increases in the same way of activation percentage. Much more remarkable is the ACF reactivity's increase observed after the second activation. By other hand, the $\mathrm{CO}_{2}$ activation scarcely produces development of the microporosity focusing on the widening of that, while with water vapour activation it takes place a continuous narrow microporosity development.

Explanation to the unusual process which takes place under $\mathrm{CO}_{2}$ activation arises from the PANOX fibres carbonization process. Therefore, the high amount of 
nitrogen-containing compounds released during the carbonization process makes possible pyrolytic deposition of these volatile compounds on the surface of fibres, which leads to both, $\mathrm{N}$ superficial enrichment and an increase in the carbonization yield. In the same way, it produces a decrease in the reactivity of the CF due to the active sites blockage as a consequence of the nitrogen-containing compounds pyrolytic deposit development. In addition, these compounds are resistant to $\mathrm{CO}_{2}$ attack, so not towards $\mathrm{H}_{2} \mathrm{O}$.

\section{Acknowledgements.}

The authors thank the Generalitat Valenciana and FEDER (PROMETEO2/2014/010), and MICINN and Plan E (CTQ2012-31762) for the financial support.

\section{References}

Alcañiz-Monge, J., Cazorla-Amorós, D., Linares-Solano, A., Oya, A., Sakamoto, A., Hoshi, K.: Preparation of general purpose carbon fibres from coal tar pitches with low softening point. Carbon 35, 1079-1087 (1997).

Alcañiz-Monge, J., Cazorla-Amorós, D., Linares-Solano, A., Yoshida, S., Oya, A.: Effect of the activating gas on tensile strength and pore structure of pitch-based carbon fibres. Carbon 32, 1277-1283 (1994). 
Alcañiz-Monge, J., Cazorla-Amorós, D., Linares-Solano, A.: Production of activated carbons: use of $\mathrm{CO}_{2}$ versus $\mathrm{H}_{2} \mathrm{O}$ as activating agent. A reply to a letter from P. L. Walker Jr. Carbon 35, 1665-1668 (1997).

Brunauer, S., Emmett, P.H., Teller, E.: Adsorption of gases in multimolecular layers. J. Am. Chem. Soc. 60, 309 (1938).

Boehm, H.P., Voll, M.: Basische Oberflächenoxide auf Kohlenstoff-I. Adsorption von säuren. Carbon. 8, 227 (1970).

Cazorla-Amorós, D., Alcañiz-Monge, J., Linares-Solano, A.: Characterization of activated carbon fibres by CO2 adsorption. Langmuir. 12, 2820 (1996).

Chiang, Y.C., Lee, C.Y., Lee, H.C.: Surface chemistry of polyacrylonitrile- and rayonbased activated carbon fibres after post-heat treatment. Mat. Chem. Phys. 101, 199-210 (2007)

Donnet, J.B., Rebouillat S, Wang T.K., Peng, J.C.M. :Carbon Fibres (3rd Edition). Marcel Dekker, New York (1998).

Dubinin, M.M.: Chemistry and Physics of Carbon, Vol. 2. Marcel Dekker, New York (1966). 
Fitzer, E., Frohs, W., Heine, M.: Optimization of stabilization and carbonization treatment of PAN fibres and structural characterization of the resulting carbon fibres. Carbon. 24, 387-395 (1986).

Freeman, J., Gimblett, F.G.R., Sing, K.I.W.: Studies of activated charcoal cloth. V. Modification of pore structure by impregnation with certain transition metal salts and oxo-complexes. Carbon 27, 85-93 (1989).

Froment, G.F.: Coke Formation in the Thermal Cracking of Hydrocarbons. Rev. Chem. Eng. 6, 293-328 (1990).

Jing, M., Wang, C., Wang, Q., Bai, Y., Zhu, B.: Chemical structure evolution and mechanism during pre-carbonization of PAN-based stabilized fibre in the temperature range of 350-600 ${ }^{\circ} \mathrm{C}$. Polym. Degrad. Stab. 92, 1737-1742 (2007).

Ko, T.H., Chiranairadul, P., Lu, C.K., Lin, C.H.: The effects of activation by carbon dioxide on the mechanical properties and structure of PAN-based activated carbon fibres. Carbon 30, 647-655 (1992).

a) Laine, N.R., Vastola, F.J., Walker, P.L.: The importance of active surface area in the carbonoxygen reaction. J. Phys. Chem. 67, 2030-2034 (1963). b) Floess, J.K., Longwell, J.P., Sarofim, A.F.: Intrinsic reaction kinetics of microporous carbons. 1: Noncatalyzed chars. Energy \& Fuels. 2, 18-26 (1988). 
Liu, J., Wang, P.H., Li, R.Y.: Physical modification of polyacrylonitrile precursor fibre: Its effect on mechanical properties. J. Appl. Polym. Sci. 52, (1994) 945-950.

Mang, D., Boehm, H.P., Stanczyk, K., Marsh, H.: Inhibiting effect of incorporated nitrogen on the oxidation of microcrystalline carbons. Carbon 30, 391-398 (1992).

Mcnair, R.N., Arons, G.N.: Carbon Adsorption Handbook, cap. 22, 819. Ann Arbor Science Pub., Ann Arbor, Mich., 1977.

Megaritis, A., Messenböck, R.C., Collot, A.G., Zhuo, Y., Dugwell, D.R., Kandiyoti, R.: Internal consistency of coal gasification reactivities determined in bench-scale reactors: effect of pyrolysis conditions on char reactivities under high-pressure $\mathrm{CO}_{2}$. Fuel 77 , 1411-1420 (1998).

Messenböck, R.C., Dugwell, D.R., Kandiyoti, R.: $\mathrm{CO}_{2}$ and steam-gasification in a highpressure wire-mesh reactor: the reactivity of Daw Mill coal and combustion reactivity of its chars. Fuel 78, 781-793 (1999).

Mittal, J., Konno, H., Inagaki, M., Bahl, O.P.: Denitrogenation behavior and tensile strength increase during carbonization of stabilized pan fibres. Carbon 36, (1998) 13271330. 
Mochida, I., Korai, Y., Shirahama, M., Kawano, S., Hada, T., Seo, Y., Yoshikawa, M., Yasutake, A.: Removal of $\mathrm{SO} x$ and $\mathrm{NO}_{x}$ over activated carbon fibres. Carbon. 38, 227239 (2000).

Park, J., Kim, K.D.: Influence of activation temperature on adsorption characteristics of activated carbon fibre composites. Carbon 39, 1741-1746 (2001).

Rahaman, M.S.A., Ismail, A.F., Mustafa, A.: A review of heat treatment on polyacrylonitrile fibre. Polym. Degrad. Stabil. 92, 1421-1432 (2007).

Raymundo-Piñero, E., Cazorla-Amorós, D., Linares-Solano, A.: The role of different nitrogen functional groups on the removal of $\mathrm{SO}_{2}$ from flue gases by $\mathrm{N}$-doped activated carbon powders and fibres. Carbon 41, 1925-1932 (2003).

Raymundo-Piñero, E., Cazorla-Amorós, D., Salinas-Martínez de Lecea, C., LinaresSolano, A.: Factors controling the $\mathrm{SO}_{2}$ removal by porous carbons: relevance of the $\mathrm{SO}_{2}$ oxidation step. Carbon 38, 335-344 (2000).

Santos Silva, I., Palma, C., Lemos, F., Ramôa Ribeiro, F., Sousa Lobo, L.: Non catalytic carbon gasification modeling. Dynamics of Surfaces and Reaction Kinectics in Heterogeneous Catalysis, in Studies in Surfaces Sciences and Catalysis. (eds.) Froment, G.F., Waugh, K.C., pp. 535-540. Elsevier Science (1997). 
Scofield, J.H.: Hartree-Slater subshell photoionization cross-sections at 1254 and 1487 eV. J Electron Spectrosc Relat Phenom. 8, 129-137 (1976).

Sing, K.S.W., Everett, D.H., Haul, R.A.W., Moscou, L., Pierotti, R.A., Rouquerol, J., Siemieniewska, T.: Reporting physisorption data for gas/solid systems with special reference to the determination of surface area and porosity. Pure Appl. Chem. 57, 603 (1985).

Song, Y., Qiao, W., Yoon, S.H., Mochida, I., Guo, Q., Liu, L.: Removal of formaldehyde at low concentration using various activated carbon fibres. J. Appl. Polym. Sci. 106, 2151-2157 (2007).

Stejskal, J., Gilbert, R.G.: Polyaniline. Preparation of a conducting polymer. Pure Appl. Chem. 74, 857-867 (2002).

Suzuki, M.: Activated carbon fibre: Fundamentals and applications. Carbon 32, 577-586 (1994).

Tavanai, H., Jalili, R., Morshed, M.: Effects of fibre diameter and CO2 activation temperature on the pore characteristics of polyacrylonitrile based activated carbon nanofibres. Surf. Interface Anal. 41, 814-819 (2009).

Vilaplana-Ortego, E., Maciá-Agulló, J.A., Alcañiz-Monge, J., Cazorla-Amorós, D., Linares-Solano, A.: Comparative study of the micropore development on physical 
activation of carbon fibres from coal tar and petroleum pitches. Micropor. Mesopor. Mat. 112, 125-132 (2008).

Walker, P.L., Rusinko, F., Austin, L.G.: Gas Reactions of Carbon. Adv.Catal. 11, 133221 (1959).

Wang, T., Sherwood, P.M.A.: X-ray Photoelectron Spectroscopic Studies of Carbon Fibre Surfaces. 17. Interfacial Interactions between Phenolic Resin and Carbon Fibres Electrochemically Oxidized in Nitric Acid and Phosphoric Acid Solutions, and Their Effect on Oxidation Behavior. Chem Mater. 6, (1994) 788-795.

Wang, P.H., Yue, Z.R., Liu, J.: Conversion of polyacrylonitrile fibres to activated carbon-fibres - effect of activation. J. Appl. Polym. Sci. 60, 923-929 (1996).

Wangxi, Z., Jie, L., Gang, W.: Evolution of structure and properties of PAN precursors during their conversion to carbon fibres. Carbon 41, 2805-2812 (2003).

Watt, W. - Chemistry and physics of conversion of PAN fibres into high-modulus carbon fibre. Strong fibre, vol.1. (eds.) Watt, W., Perov, B.B., p. 327, Elsevier Science Publishers, Netherlands (1985).

Ryu, S.K., "Porosity of Activated Carbon Fibre". High Temperature - High Pressure. 22,345-354 (1990). 
Ryu, S.K., Jin, H.K., Gondy, D., Pusset, N., Ehrburger, P.,"Activation of Carbon Fibres by Steam and Carbon dioxide". Carbon. 31, 841-842 (1993).

Ryu, S.K., Lee, J.K., Lee, D.W., Pusset, N., Ehrburger, P., "Adsorption Characteristics of Activated Pitch-based Carbon Fibres". Carbon'90, Paris, France, July 16-20 (1990).

Ryu, S.K., Ko, K.Y., Rhee, B.S., Ehrburger, P., "Density and Pore Volume of Activated Carbon Fibres". Proc. 21st Biennial Conf.on Carbon, June 13-18, Buffalo, USA, 623 (1993)

Yusofa, N., Ismail, A.F.: Post spinning and pyrolysis processes of polyacrylonitrile (PAN)-based carbon fibre and activated carbon fibre: A review. J. Anal. Appl. Pyrol. 93, 1-13 (2012).

Zaini, M.A.A., Amano, Y., Machida, M.: Adsorption of heavy metals onto activated carbons derived from polyacrylonitrile fibre. J. Hazard. Mater. 180, 552-560 (2010) 


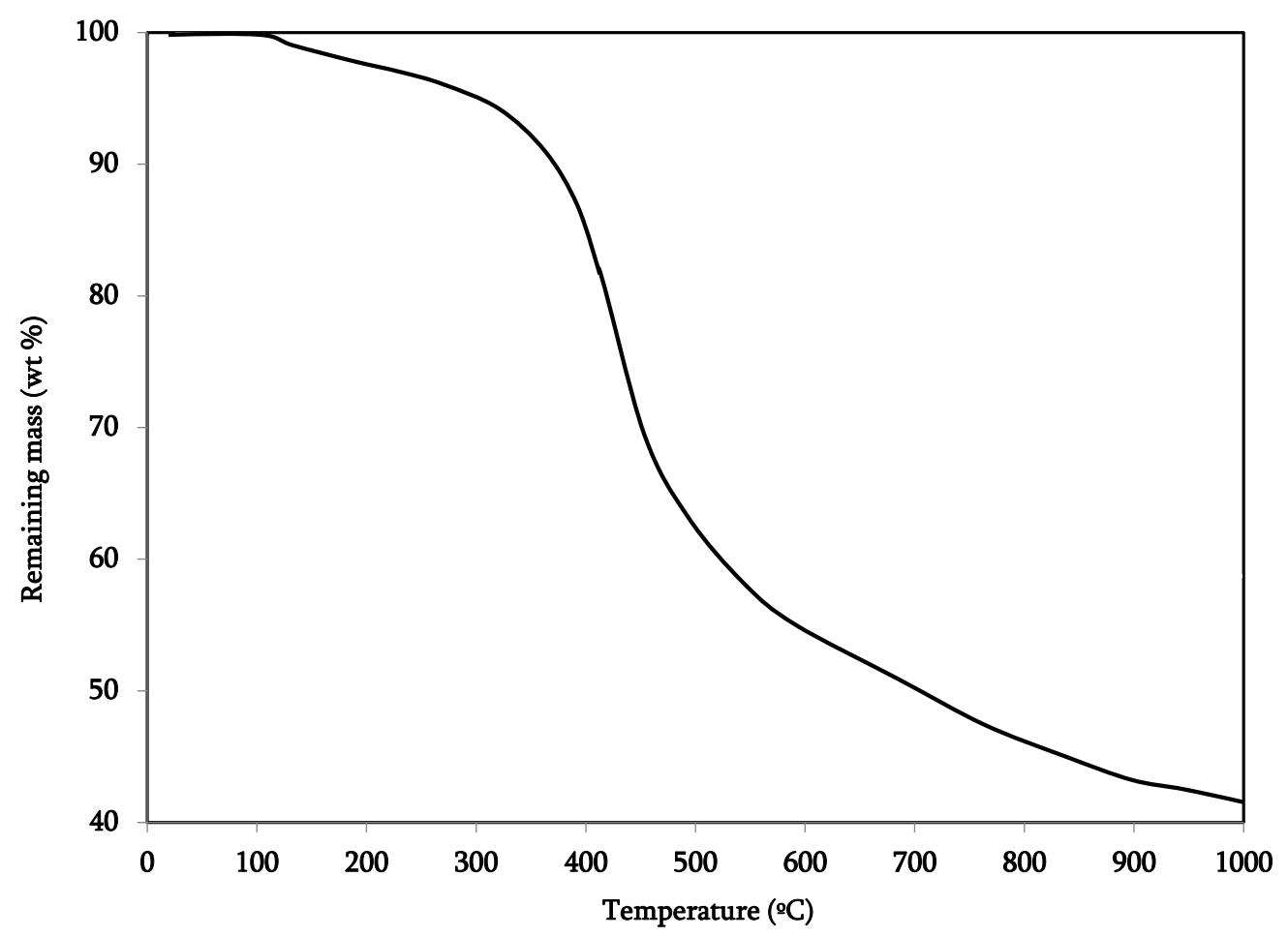

Figure 1. Thermogravimetric curve of the original PANOX fiber. 


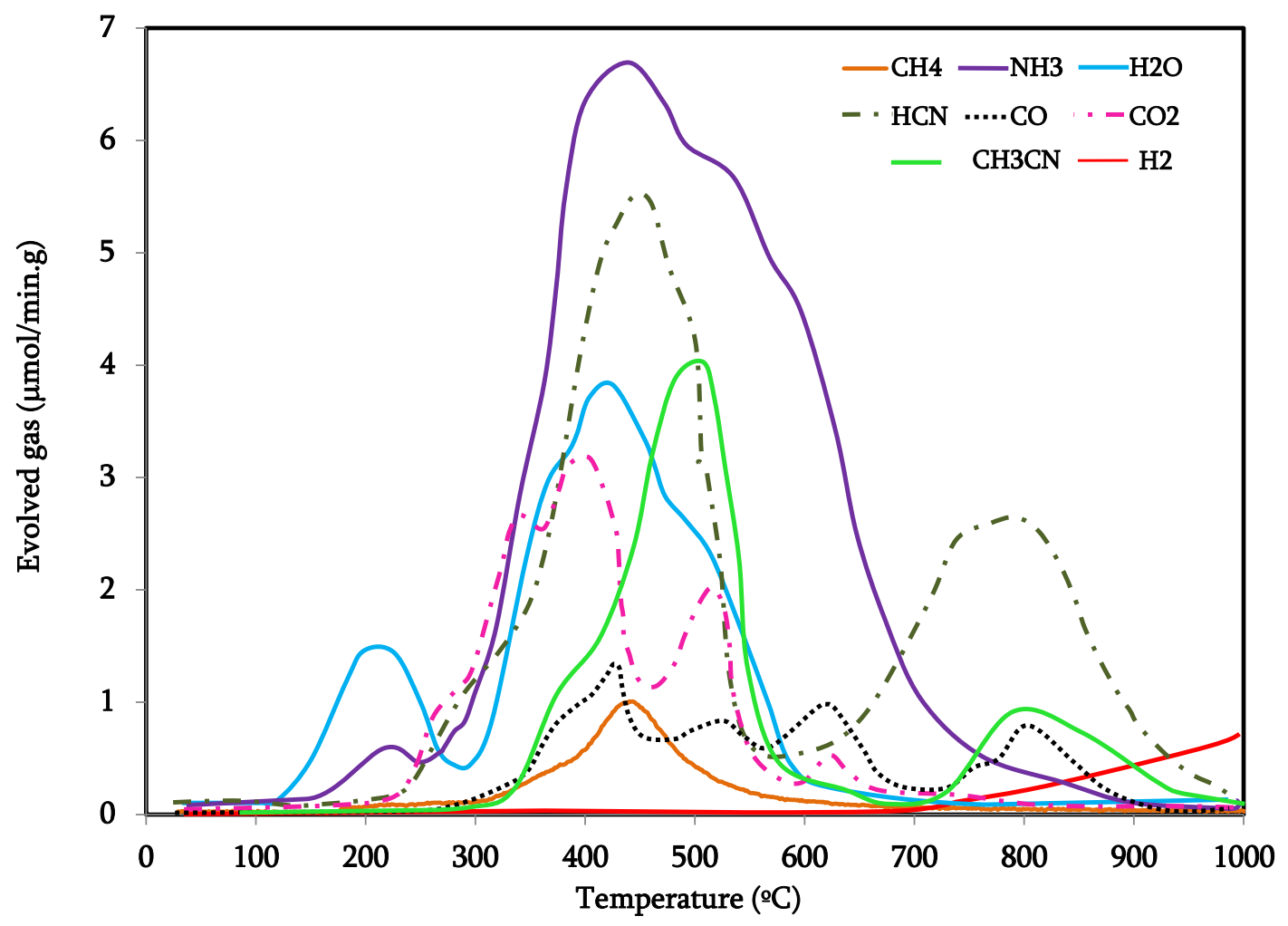

Figure 2. Evolution profiles of the evolved gases by the PANOX fibers during the carbonization process. 


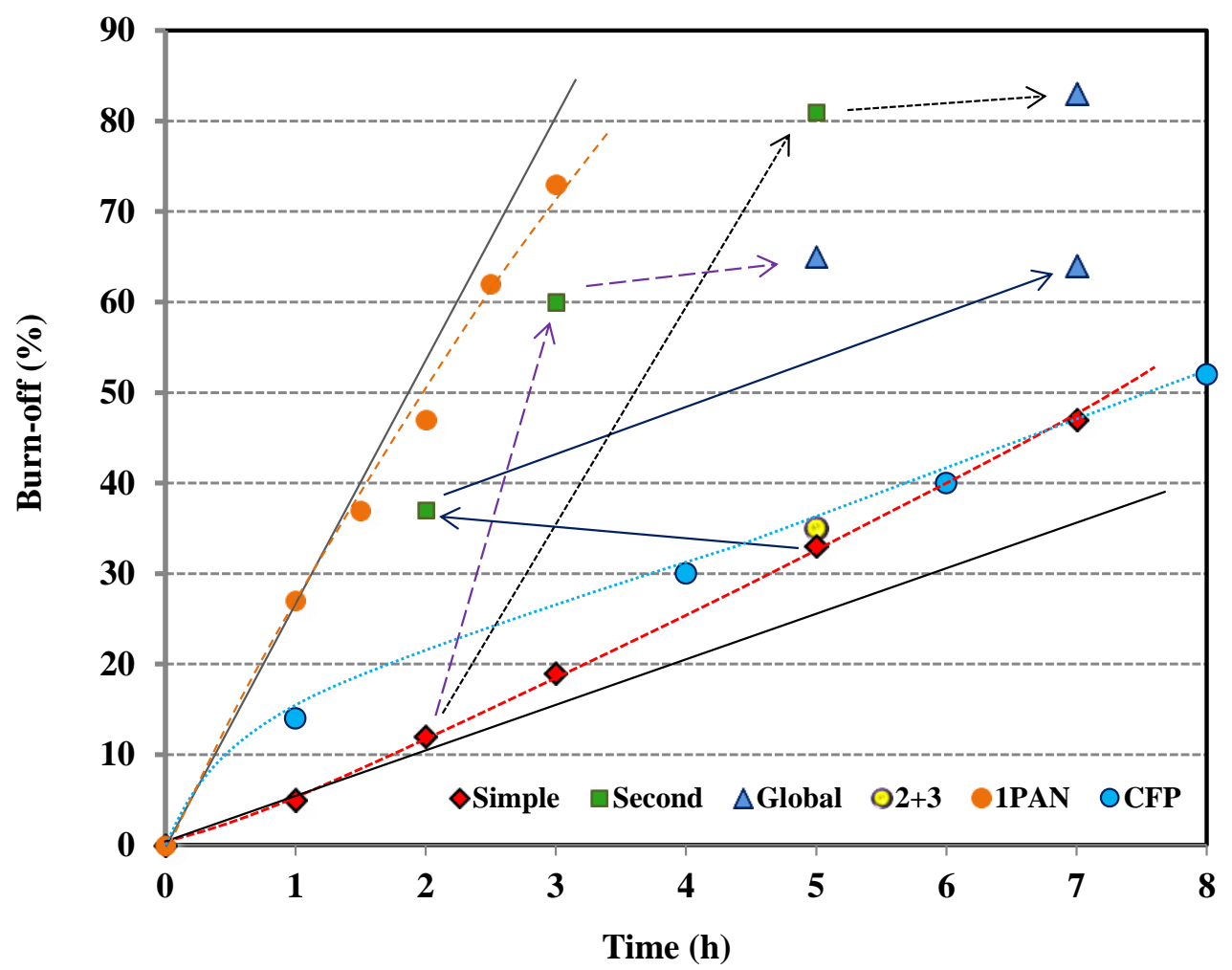

Figure 3. Evolution of the burn-off percentage versus time for the activation of $\mathrm{CF}$ 10PAN with $\mathrm{CO}_{2}$; in one stage (Simple), in a second activation of the activated (Second), for the CFP and for the CF 1PAN (1PAN). 


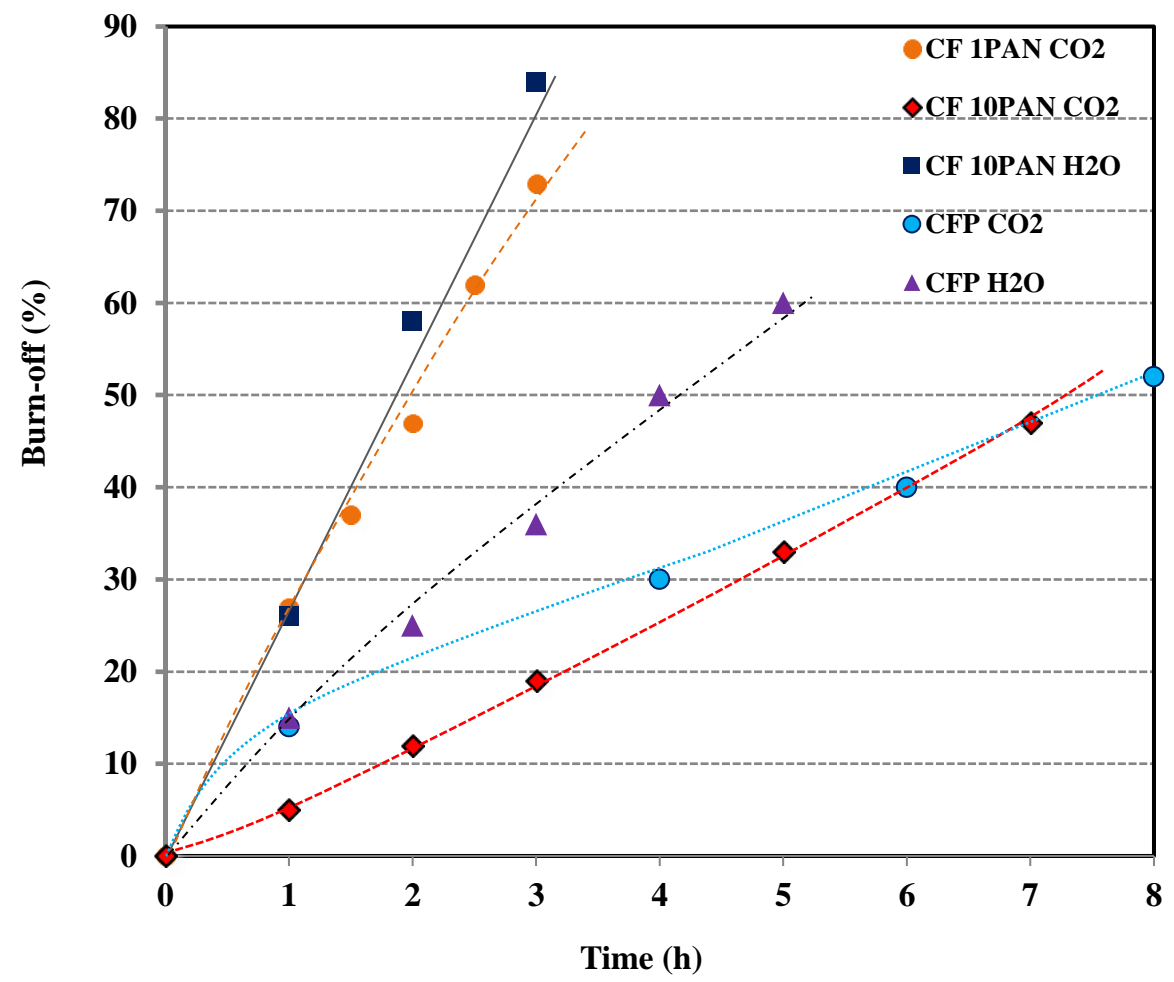

Figure 4. Burn-off percentage evolution over the time for CFP and CF 10PAN activated with $\mathrm{H}_{2} \mathrm{O}$ and $\mathrm{CO}_{2}$, and for $\mathrm{CF}$ 1PAN activated with $\mathrm{CO}_{2}$. 


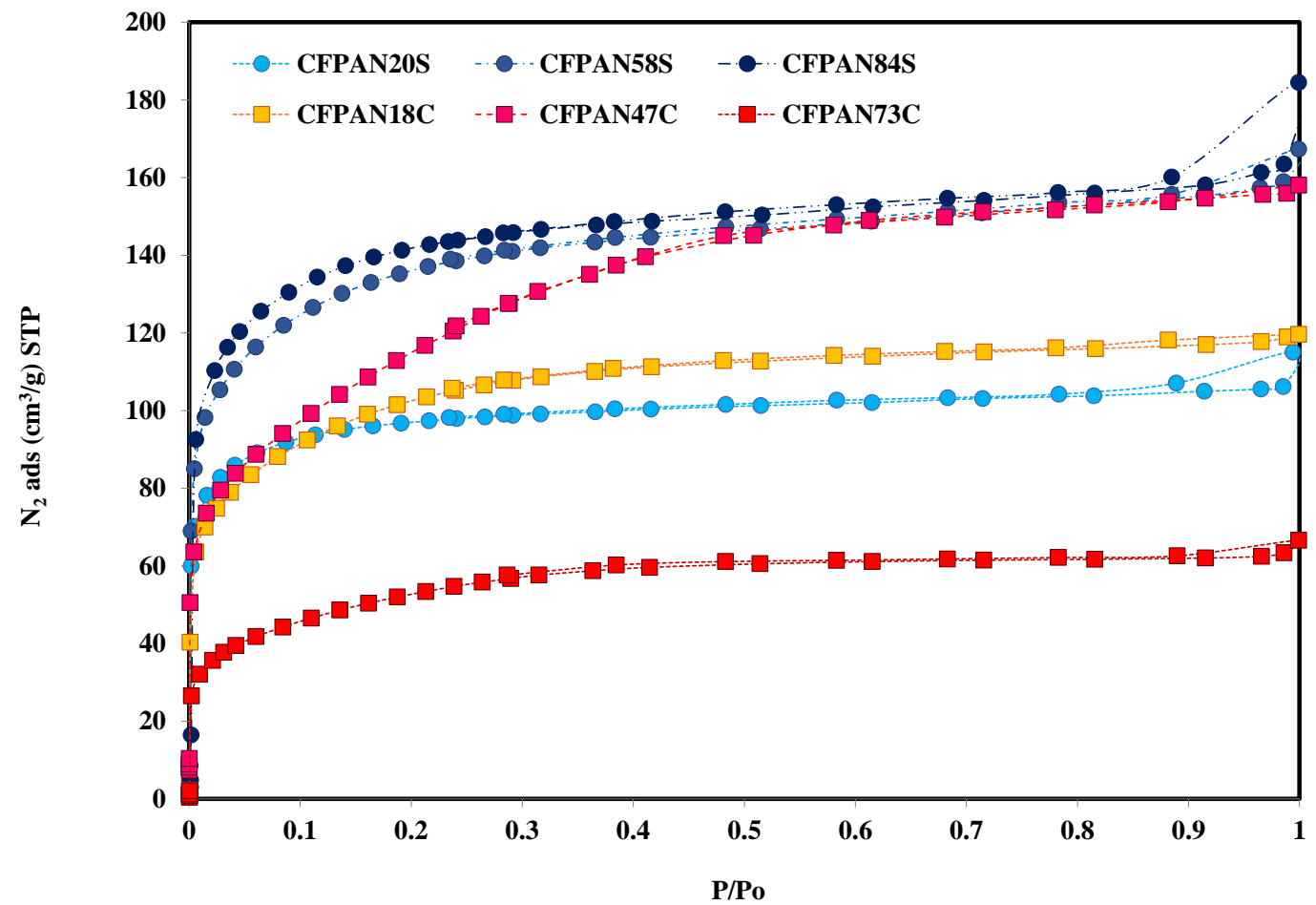

Figure 5. $\mathrm{N}_{2}$ adsorption isotherms of ACF 10PAN activated with $\mathrm{CO}_{2}$ (series CFPAN-

C) and with water vapor (series CFPAN-S). 
